\title{
Enzimatic Kinetic Resolution of Alkynylic Diols
}

\author{
Nascimento, R. X. (IC) ${ }^{1}$, Ferreira, J. G. (PG) ${ }^{1}$, Princival J. L. (PQ) \\ 'Departamento de Química Fundamental, Universidade Federal de Pernambuco (UFPE), 50739-901, Recife (PE), Brasil \\ *princivalj@yahoo.com.br
}

Keywords: Diols, Kinetic Resolution, Enzyme.

\section{INTRODUCTION}

Diols containing stereogenic centers are importants precursors in organic synthesis, particularly in the synthesis of substituted lactones. The enzimatic kinetic resolution is a tool widely used to obtain enantiomericaly enriched compounds. Few studies involving the resolution of alkynylic diols are reported in the literature. In most cases the resolution is carried out using alcohols without another functionality. ${ }^{1}$ In the present work, we prepared alkynylic diols that will be subjected to the kinetic resolution, making possible their obtention in optically active forms. This class of compounds can be used in synthesis of bioactive chiral butenolides, an important class of compounds with biological activity. $^{2}$

\section{RESULTS AND DISCUSSION}

Initially, the aldehydes 1a-d and epoxide 1e were submitted to addition and substitution reactions respectively with lithium alkynyl leading the formation of the diols 2a-e in good yields (Scheme 1).

$$
\text { 3) }\left[\begin{array}{ccc}
\mathrm{NH}_{4}^{\prime} \mathrm{Cl}_{(\mathrm{aq})} \\
\text { 1a-d }
\end{array}\right]
$$

\begin{tabular}{|l}
\multicolumn{1}{c}{ yields $55-65 \%$} \\
\begin{tabular}{|l} 
2a. $n=1, R=M e, R^{\prime}=H$ \\
2b. $n=1, R=M e, R^{\prime}=M e$ \\
2c. $n=1, R=M e, R^{\prime}=P h$ \\
2d. $n=1, R=H, R^{\prime}=$ furfuryl \\
2e. $n=2, R=M e, R^{\prime}=M e$
\end{tabular}
\end{tabular}

Scheme 1. Syntheses of the alkynylic diols.

The racemic diol 2a was submitted to enzymatic kinetic resolution using CAL-B as biocatalyst, vinyl acetate as acyl donor and hexane as solvent (Scheme 2).

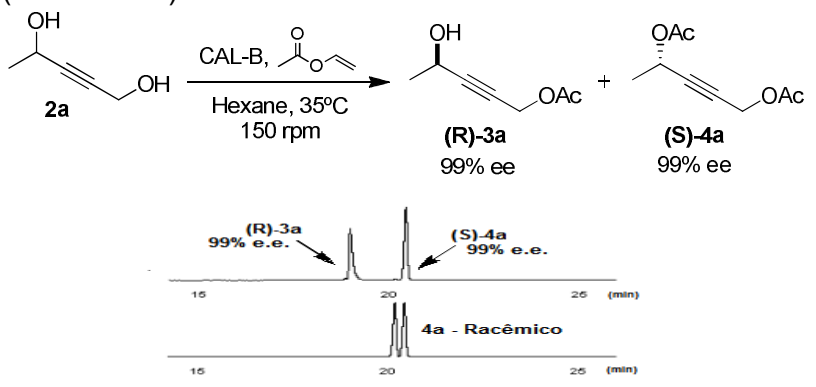

Scheme 2. Kinetic resolution of the diol $\mathbf{2 a}$.
Preliminary results of these initial studies are showed in table 1.

Table 1. Results of the kinetic resolution of $\mathbf{2 a}$.

\begin{tabular}{cccc}
\hline Entry & Time $(\mathrm{h})$ & ee 3a $(\%)$ & ee $4 \mathbf{a}(\%)$ \\
\hline 1 & 0,5 & 62,2 & 85,9 \\
2 & 1 & 69,3 & 38,6 \\
3 & 2 & 79,9 & 59,8 \\
4 & 3 & 82,0 & 64,0 \\
5 & 4 & 94,4 & 88,8 \\
6 & 5 & 97,0 & 94,0 \\
7 & 6 & 99,0 & 99,0 \\
8 & 7 & 97,1 & 98,5 \\
9 & 8 & 98,0 & 98,4 \\
10 & 9 & 94,9 & 98,3 \\
11 & 48 & 92,4 & 84,8 \\
\hline
\end{tabular}

The resolutions of the diols 2a-e using CAL-B are under investigation. Although when enantioenriched diols 2a and $\mathbf{2 d}$ wiil be applied, chiral butenolides $\mathbf{5}$ can be prepared (Scheme 3).

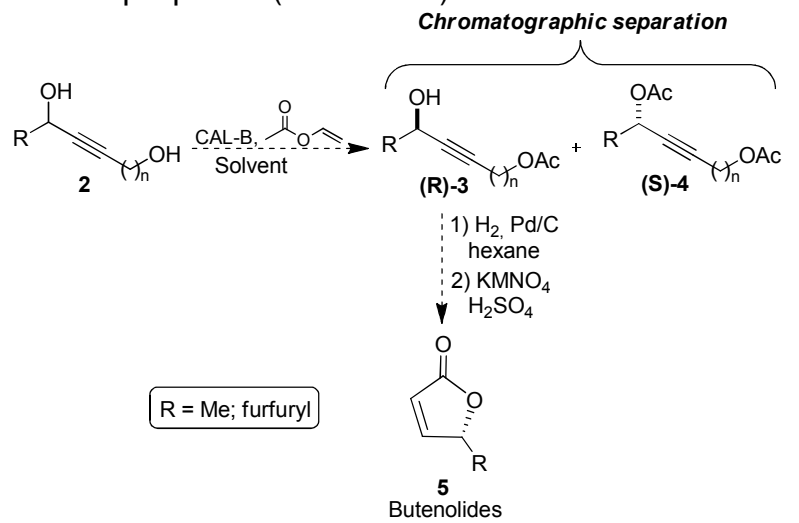

Scheme 3. Synthesis of the butenolides.

\section{CONCLUSION}

The preliminary results showed that alkynylic diols were obtained in good chemical yields and $\mathbf{2 a}$ was resolved by enzymatic kinetic resolution using CAL$B$. The application of these in the synthesis of bioactive chiral butenolides are under investigation.

\section{ACKNOWLEDGEMENTS}

PRONEX-CNPq; FACEPE; INCT-INAMI; CAPES.

\section{REFERENCES}

(a) Xu, D.; Li, Z.; Ma, S.; Tetrahedron Lett., 2003, 44, 6343. (b) Raminelli, C.; Comasseto, J. V.; Andrade, L. H.; Porto, A. L. M Tetrahedron: Asymmetry 2004, 15, 3117.

${ }^{2}$ Bassora, B.K : Costa, C. E · Gariani, R. A · Comasseto, J. V : Santos, A.

A.; Tetrahedron Lett., 2007, 48, 1485. 